\title{
The Study of Wave Warning Indexes for Ships
}

\author{
Q. Yang, J. J. Ou, N. L. Huang, and Y. P. Li
}

\begin{abstract}
Using observations and model forecasts, warning index system reflecting wave's effects on ships is formed, including indexes of wave-ship resonance, wave shoaling effect index, wave steepness index and swell proportion index. Wave-ship resonance indexes contain rolling resonance index (the rate of encountering wave period to ship's inherent rolling period), pitching resonance index (the rate of encountering wave period to ship's inherent pitching period) and heaving resonance index (the rate of encountering wave period to ship's inherent heaving period). Knowing distributions of the wave-ship resonance indexes which depend on wave period and wave direction, ships can make timely adjustment by changing their speed and direction to avoid being in resonance state. Wave shoaling effect index is the rate of wave height to its original wave height. It always reveals a semi-tidal character and has tight links with the unique topography, water level change and current variation in the Yangtze River estuary. Wave steepness index and swell wave proportion index are both extracted from wave spectra, the former tells the steepness of wave and the latter is useful to judge wave's effect on ship's momentum and cable tension. These indexes describe different aspects of wave's impacts on ships, which can be used efficiently to protect ship's sail and mooring safety.
\end{abstract}

Index Terms-Yangtze river estuary, wave warning, wave-ship resonance, shoaling effect.

\section{INTRODUCTION}

The Yangtze River estuary owns the Yangshan Port which is the maximum throughput port in China. Ships come and go frequently, needing refine marine meteorological forecast service. Wave is one of the most important sea conditions for ship's sail and mooring safety [1], [2]. The Yangtze River estuary is located around $30^{\circ} \mathrm{N}$, weather activities are complex, having obvious monsoon climate, active extratropical cyclones and several typhoons every year, there are always big waves $(2.5 \mathrm{~m} \leqslant \mathrm{Hs}<4.0 \mathrm{~m})$, heavy waves $(4.0 \mathrm{~m} \leqslant \mathrm{Hs}<6.0 \mathrm{~m})$, and even rough waves $(6.0 \mathrm{~m} \leqslant \mathrm{Hs}<9.0 \mathrm{~m})$ and precipitous waves $(9.0 \mathrm{~m} \$ \mathrm{Hs}<$ 14.0m). Supper Typhoon 'Muifa' numbered 201109, showed its huge power along the east coast of China [3], in the Yangtze River estuary area, the highest wind speed reached $42.7 \mathrm{~m} / \mathrm{s}$ and the highest wave height reached $11.3 \mathrm{~m}$ which are both observed by Hai Jiao Buoy $\left(30.409^{\circ} \mathrm{N}\right.$, $\left.122.928^{\circ} \mathrm{E}\right)$. High waves usually bring shipwreck incidents

Manuscript received November 21, 2016; revised April 21, 2017. This work was supported in part by the Program of Shanghai Meteorological Bureau, No. MS201603.

Q. Yang is with Shanghai Ocean University, and with Shanghai mariNe Meteorological Center, Shanghai, China (e-mail: yangqiabuwanju@163.com).

J. J. Ou, and N. L. Huang are with Shanghai Marine Meteorological Center, Shanghai, China (corresponding author: N. L. Huang e-mail: hn1873211@gmail.com).

Y. P. Li is with Shanghai Typhoon Institute of China Meteorological Administration, Shanghai, China. and cause invocatable damages.

Wave height is not only affected by wind, but also by topography, current and water level [4], [5]. Because of its own topographic character, Yangtze River estuary has obvious shoaling effect and it's an important factor for ship sailing safety. When waves travel from deep water to shallow water, their energy remains unchanged but group velocity decreases, thus wave height increases fast, and leading to subversive and continuous big waves and even ship grounding and sinking. Not only that, wave height is also affected by current and water level. Influence of water level variation on wave height is similar to topographical change in shoaling effect, and impact of current on waves are mainly through Doppler effect [6]. Lambrakos et al. [7] observed wave-current interaction effect on wave speed and spectrum. And in observation of Wolf and Prandle [8], wave height, period, steepness and high frequency wave direction are varying semi-diurnally with tide. Because East China sea is a wide marginal sea and trumpet-shaped which is beneficial for tidal energy to focus, thus in the Yangtze River Estuary tidal range is large and tidal current is strong, the maximum speed may reaches to $100-200 \mathrm{~cm} / \mathrm{s}$ [9]. Therefore, effect of tidal current and tidal level on waves must be noted.

Besides wave height, waves' impacts on ships are also due to their steepness and components. Wave steepness describes slant degree of wave surface; it is defined as rate of wave height to wave length. But wave length is not directly obtained by measurements, and is calculated from wave period and water depth [10]-[12], or by empirical method [13], so there exists uncertainty in some degree. By distinguishing wave's components, waves are divided into wind waves, swell waves and mixed waves [14]. Their characters show clear differences on their energy distribution along frequency axis of wave spectrum [15]. Among them mixed waves, especially long period mixed waves, have the max influence on mooring ships which may lead to ship swing and cable rupture, or even ship sinking [16], [17].

Ship's own character together with sailing speed and direction can make a same wave to exert different impacts on a same ship [18]. Sailing ships influenced by many factors such as waves from environment which may produce various swing motions, and violent oscillation which may threaten ship safety [19].

Because of the complexity of waves and their complex impacts on ships, how to make out target and efficient wave warning for ships is still needed to be studied further.

A large amount of studies have discussed the impact of topography, current and water level on waves, especially impact of wave-current interaction from energy point of view [20]-[22], and wave action flux conservation is applicable to linear surface wave [8]. Based on wave action 
flux conservation law, Bai, Li and Wang [6] obtained wave height variation expression along a wave ray when fluid speed and tidal level are both varying. Wang and $\mathrm{Li}$ [23] pointed out that under wave action flux conservation when Stokes waves propagate against or travel with exponential profile current, waves' characteristic changes, and nonlinear effect is more obvious when waves propagate against current and especially when both waves and current are strong. Though there are many theoretical study achievements on waves, their application on forecast operation are still needed to be carried on. SWAN model including effect of tide and topography [24], [25] advances forecast result of wave height, but to a certain extant is depended by precision of topographical data, timeliness of assimilation of buoy observations and gauge data, and accuracy of wind field. At present plenty of observation facilities are built in the Yangtze River estuary, if real-time observations can be used in wave analyzing, monitoring and early alarming, better results could be expected.

In aspect of describing wave steepness, using high frequency wave height observation, wave steepness classes are defined and plotted in real-time by NOAA [15]. This method does seize the differences between spectra of different kind of waves, and has clear physical meaning. But good method of quantitatively analyzing impact of different kinds of waves on mooring ships still has not been seen.

Ship's inherent period is related to resonance motions [26]; the rate of encountering wave period to ship's inherent period is applied to judge if resonance is to come up or not. But the result manifests in a complex table form [27] and lacks blending of observations or model results in real-time, therefore needs to be improved to be used in practical operation.

So in order to release targeted wave warnings, it is urgent to form an index system to analyze waves' impacts on ships. Four factors threatening ship safety are considered which are effect of shallow topography and current and level on waves, wave steepness, effect of swell on mooring ships and wave-ship resonance. Solutions in wave warning index system contain two indexes already exist which are steepness index and resonance indexes, and the other two indexes designed originally which are shoaling effect index and swell wave proportion index. All these indexes can be calculated by data from observations or model results, and can be checked quickly, conveniently and precisely from corresponding figures. This would be helpful for ships to avoid dangers from waves and guarantees ship safety.

\section{WAVE WARNING INDEXES}

\section{A. Wave Shoaling Effect Index}

Wave shoaling effect index is designed to reflect accurately the impacts of topography, tidal level and tidal current on wave height. It is defined as the rate of wave height to its original height. Basing on the wave height change formula [6], reserving the shoaling factor and the Doppler factor and doing reasonable simplification, wave shoaling effect index in situation of different topographic depth, current speed and water level is calculated.

According to conservation law of wave action flux, for a small amplitude gravity wave, wave height variation along a wave ray is [6]:

$$
H / H_{0}=K_{f} K_{r} K_{\delta} K_{s}
$$

$K_{f}$ is coefficient of friction, $K_{r}$ is coefficient of refraction. Ignoring $K_{f}$ and $K_{r}$, wave height variation could be simplified as:

$$
H / H_{0}=K_{\delta} K_{s}
$$

$K_{\delta}$ is coefficient of Doppler, $K_{\delta}=\sqrt{\delta / \delta_{0}}$, and because of $\delta=\delta_{0}-\vec{K} \cdot \vec{U}$, there is:

$$
K_{\delta}=\sqrt{\left(\delta_{0}-\vec{K} \cdot \vec{U}\right) / \delta_{0}}
$$

Here $\delta$ is intrinsic circular frequency at any point along a wave ray, $\delta_{0}$ is intrinsic circular frequency far at infinity in deep water, $\vec{K}$ and $\vec{U}$ are respectively the complexor of wavenumber and the complexor of fluid speed at any point along a wave ray. The other term $K_{s}$ is coefficient of shoaling:

$$
K_{s}=\sqrt{C_{g 0} /\left(\vec{K} \cdot \vec{U}+C_{g}\right)}
$$

$C_{g 0}$ is group velocity far at infinity, $C_{g}$ is group velocity at any point along a wave ray.

Next, variables in formula above-mentioned are replaced by variables getting from observations, in order to employ the formula to be used conveniently in daily marine meteorological forecast. Substitute $\delta_{0}$ in (2.3) by $\delta_{0}=\sqrt{g k_{0}}$ [12], $k_{0}$ is scalar of wavenumber far at infinity, thus there is:

$$
K_{\delta}=\sqrt{\left(\sqrt{g k_{0}}-\vec{K} \cdot \vec{U}\right) / \sqrt{g k_{0}}}
$$

In (2.4), because far at infinity in deep water $C_{g 0}=\frac{1}{2} C_{0}$, $C_{0}$ is phase velocity far at infinity in deep water and $C_{0}=\sqrt{g / k_{0}} \quad$, thus $C_{g 0}=\frac{1}{2} \sqrt{g / k_{0}} \quad$ and $C_{g}=\beta \sqrt{\frac{g}{k} \tanh (k h)}, h$ is water depth containing topological depth and tidal level, $k$ is scalar of wavenumber at any point along a wave ray, $\beta=\frac{1}{2}\left(1+\frac{2 k h}{\sinh (2 k h)}\right)$, so there is:

$$
K_{s}=\sqrt{\frac{1}{2} \sqrt{g / k_{0}} /\left(\vec{K} \cdot \vec{U}+\frac{1}{2}\left(1+\frac{2 k h}{\sinh (2 k h)}\right) \sqrt{\left.\frac{g}{k} \tanh (k h)\right)}\right.}
$$

Both in (2.5) and (2.6), $k_{0}=k \tanh (k h), k=\frac{2 \pi}{\lambda}$, 
$\lambda$ has different expressions in shallow water and in deep water and is function of wave period and water depth [12]. So both $K_{\delta}$ and $K_{s}$ can be calculated by relative current speed $\vec{K} \cdot \vec{U}$, wave period $T$ and water depth $h$, and all these variables can be obtained or calculated from observations.

\section{B. Wave Steepness Index and Swell Wave Proportion Index}

Wave steepness is used to describe tilt degree of wave surface from crest to trough. When wave is not very high, steep wave can also cause damage, so its destruction is secluded. Basing on NOAA's calculation method, wave steepness is divided into four levels [15], here it is adopted as wave steepness index.

For mooring ships, wave imposes its impact on ships' momentum and cable tension, and mixed wave has strongest impact. For the same total energy, the more energy the low frequency part accounts, the more impact wave exerts [16]. Thus swell wave proportion index $S r$ is designed to represent the proportion of the low frequency energy, its expression is:

$$
S r=\frac{\int_{f_{\min }}^{f_{x}} s(f) d f}{\int_{f_{\min }}^{f_{\max }} s(f) d f}
$$

$s(f)$ is wave spectrum function obtained from fast Fourier transform, $f_{\min }$ and $f_{\max }$ are respectively the minimum and maximum frequency of wave spectrum, and dividing frequency $f_{x}$ between swell wave and wind wave is defined by NOAA [15].

\section{Wave-Ship Resonance Indexes}

The wave period relative to ship voyage is called encountering wave period. When ship's rolling period, pitching period or heaving period is close to encountering wave period, ship rocks more and more intensely even to cause shipwreck. Due to different ship parameters such as ship's length, width, initial metacentric height and draught, the same wave may lead to different impacts on different ships. Even for a same ship, because of its different sail direction and speed, the same wave will also cause different influences. The graphics of wave-ship resonance indexes have taken this problem into account that encountering wave period changes with wave's state and ship's direction and speed, and due to their own rolling, pitching and heaving period, targeted wave warnings will be sent to different kinds of driving ships.

If wave direction, wave length, voyage direction and speed are known, then encountering wave period can be calculated. Encountering wave period distribution for different driving directions and speeds of ships is drawn in polar coordinate. And the encountering wave periods close to ship's inherent period are marked out in the polar figure, either are their corresponding ship directions and speeds. Then the dangerous speed and direction range for the ship in this state of wave movement are obviously labeled. When the rate of encountering wave period to ship's inherent rolling period, pitching period or heaving period is between
0.7 to 1.3 , wave warning should be sent.

\section{APPLICATIONS AND CASES}

\section{A. Wave Shoaling Effect Index}

Fig. 1 (b) shows wave height changes by shoaling effect when current and water level variation are not considered. For a fixed water depth in coastal area, such as $7 \mathrm{~m}$, lines in the lower location represent waves of smaller wave periods, and vice versa. Traveling from deep water to shallow water wave height grows; waves with larger period manifest shoaling effect more obviously. For example, for a wave of 12 second period, its wave height at depth of $5 \mathrm{~m}$ can reach to 1.2 times of its original value.
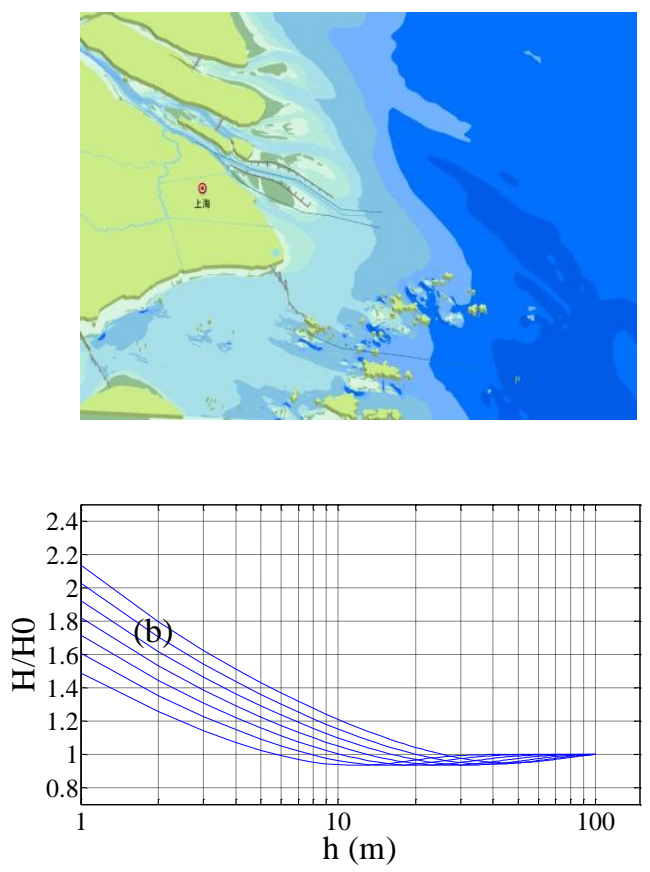

Fig. 1. (a) Topography of Yangtze River estuary and Fig. 1 (b) wave height changes with depth (curls from low to high represent waves with periods of $6,7,8 \ldots \ldots 12 \mathrm{~s}$ respectively), horizontal ordinate is water depth and vertical ordinate is the shoaling effect index (the rate of wave height to its original value).

Fig. 2 gives an example to show when considering shoaling effect and Doppler effect, how wave height changes due to different relative current speed and water depth. In Yangtze River estuary, tidal current and tidal level have the semi-diurnal variation characteristics. For the same water depth and the same relative current speed, there is the largest discrepancy of wave height between wave in upstream with low tide and wave in downstream with high tide. Wave height in upstream with low tide (e.g. relative speed is $-2 \mathrm{~m} / \mathrm{s}$, water depth is $4 \mathrm{~m}$, wave height change rate is 1.4 ) can be 1.8 times of that in downstream with high tide (e.g. relative speed is $2 \mathrm{~m} / \mathrm{s}$, water depth is $6 \mathrm{~m}$, wave height change rate is about 0.8 ).

Fig. 3 (a d) shows wave height variation (red lines) (calculated by formula: wave height - wave height / shoaling effect index), containing shoaling and Doppler effect during Typhoon Wipha in 2013, from 8 o'clock 14thto 8 o'clock 17th in October. Subfigures (a d) represent different stations of Don Tan, Nan Cao, Kou Wai and Hai 
Jiao respectively. Thus using wave shoaling effect index, wave height variation caused by shoaling and Doppler effect can be clearly displayed and large wave height variation can be timely alarmed. Not only that, counting shoaling effect index from long and multi-station historic observations, significant time periods and coastal ocean regions sensitive to shoaling effect and Doppler effect would be found out.

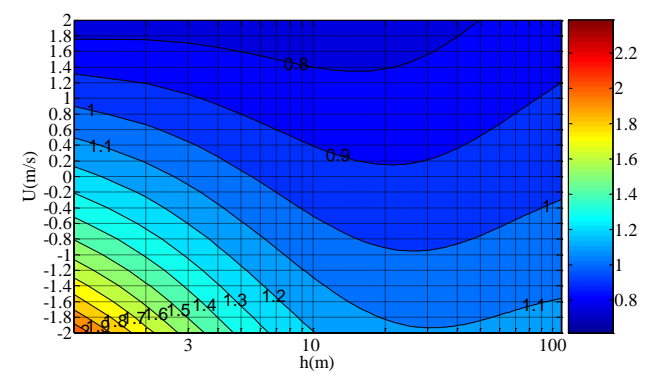

Fig. 2. Contour lines of wave height change rate (the rate of wave height to its original value), here the wave period is 8 second, horizontal ordinate

is water depth and vertical ordinate is relative current speed.
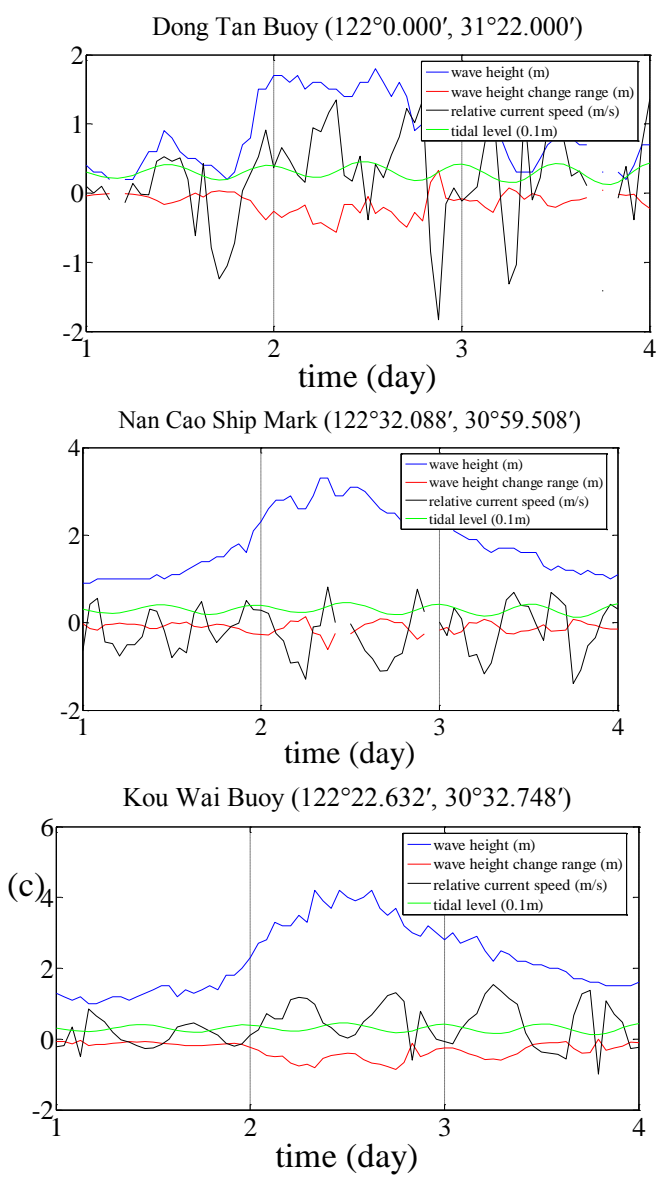

(d) Hai Jiao Buoy $\left(122^{\circ} 55.680^{\prime}, 30^{\circ} 24.588^{\prime}\right)$

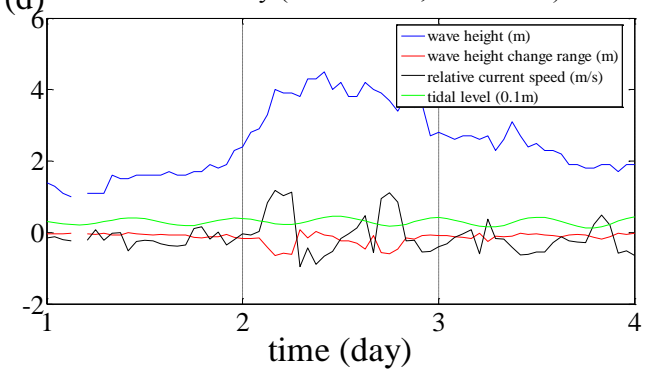

Fig. 3. Wave height variation (red line)(unit: $\mathrm{m}$ )due to shoaling and Doppler effect, blue lines are observed wave height (unit: $\mathrm{m}$ ), green lines are tidal level (unit: $0.1 \mathrm{~m}$ ), black lines are relative current speed (unit: $\mathrm{m} / \mathrm{s}$ ).

\section{B. Wave Steepness Index and Swell Wave Proportion Index}

Fig. 4 draws wave steepness level variation from April 1th to 10th in 2011. It was weak wind blowing from southward on 1th, and the wind turned to be much stronger and come from a steady northern direction from late of 2th, and after 4th the wind became smaller and smaller. Wave steepness index rose up to Level Three after wind direction turns to north on 2th; and during 3th and 4th wave height was not bigger than $1.5 \mathrm{~m}$, while wave steepness index of Level Three still sustained.

Fig. 4 also draws swell energy proportion and swell wave height and wind wave height are also shown. It is clear that during the north wind process from later 2 th to 4 th, every time when wind wave height became smaller, swell wave proportion index rose up simultaneously with swell wave height getting higher. That means for mooring ships the dangerous period does not only appear in gale time, it can also exist when wind is weaker and swell part of wave begins to play a dominate role in spectrum.

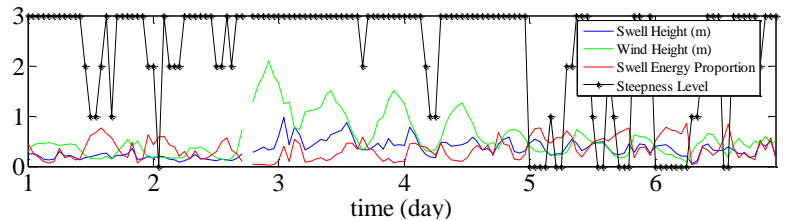

Fig. 4. Wave steepness level (black line, $-1=\mathrm{NaN}, 0=$ swell, $1=$ average, $2=$ steep, $3=$ very steep), and swell wave height (blue line, unit: $\mathrm{m}$ ), wind wave height (green line, unit: $\mathrm{m}$ ) and swell energy proportion (red line) from April 1th to 10th in 2011 .

\section{Wave-Ship Resonance Indexes}

For example, to judge whether there exists rolling resonance, firstly encountering period should be calculated and the formula is as this [26]:

$$
T_{E}=\frac{\lambda}{\left|V_{w}+V_{s} \cos \psi\right|}
$$

Here $V_{w}$ means wave speed $(\mathrm{m} / \mathrm{s}), V_{s}$ means ship speed $(\mathrm{m} / \mathrm{s}), \lambda$ represents wave length $(\mathrm{m}), \psi$ represents the angle between the ship driving direction and the direction of the encountering wave.

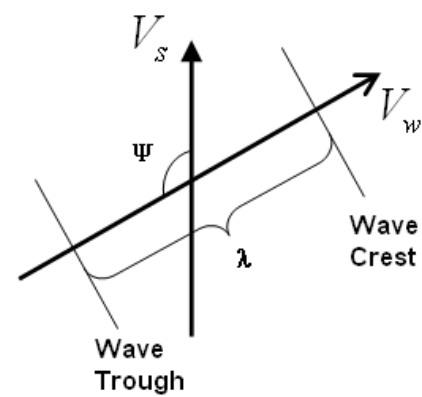

Fig. 5. Sketch figure of parameters in formula of encountering period calculation.

The encountering wave period distribution is shown in Fig. 6 (a), where wave direction is $100^{\circ}$, wave period is $7 \mathrm{~s}$, wave length is $150 \mathrm{~m}$ and the ship's inherent rolling period is 8s. In Fig. 6 (a) different colors representing different wave 
encountering periods (red: >14s, magenta: 10-14s, yellow: 6-10s, green: <6s). When ship drives to northeast direction of $30^{\circ}$ and ship speed is $10 \mathrm{kt}$, it is then in the yellow area, corresponding to encountering wave period of 6-10s. If the ship accelerates to $30 \mathrm{kt}$, then it is in the green area, corresponding to encountering wave period less than $6 \mathrm{~s}$. The rate of encountering wave period to ship's inherent rolling period is shown in Fig. 6 (b), where only rates between 0.7 to 1.3 are represented in yellow colour, and rates between 0.95 to 1.05 are represented by red. In state of yellow area of Fig. 6 (b) ship is easy to resonate with wave, and the closer it gets to the red area the more heavily it rocks to sink. Figures of encountering period of ship pitching and heaving states are the same as that of rocking.
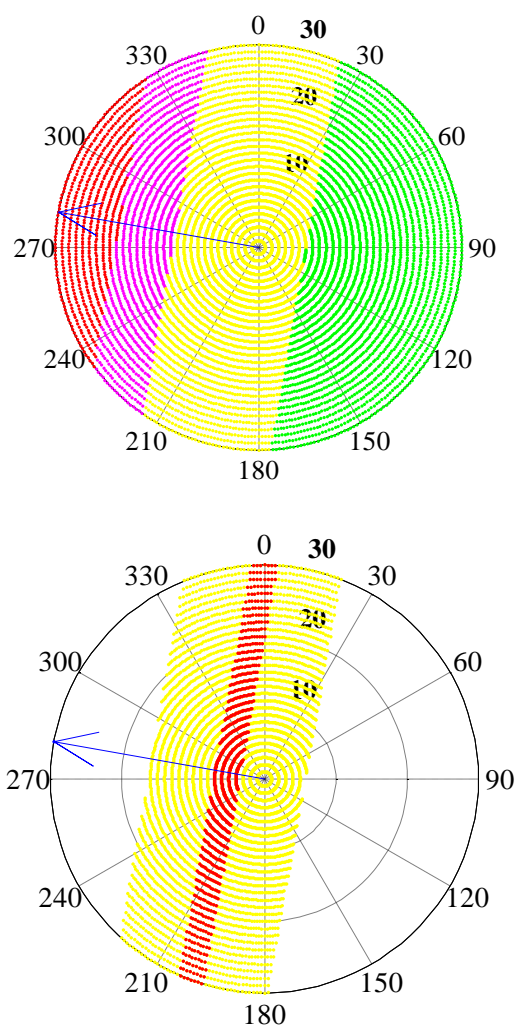

Fig. 6 (a). Wave encountering period distribution, (b)The distribution of rates of encountering wave periods to ship's inherent rolling period. In both Fig. 6 (a)and (b), arrow represents wave direction, 10, 20 and 30 on radius represent ship's driving speed $(\mathrm{kt}), 0,30,60 \ldots . .330$ on circumference represent directions of ship $\left({ }^{\circ}\right)$.

\section{CONCLUSIONS}

Aiming at reflecting different aspects threatening on ships, wave warning index system is formed. Index system contains wave shoaling effect index, wave steepness index, swell wave proportion index and wave-ship resonance indexes. Wave shoaling effect index simplifies complex wave theories, wave height variation with and without current and tidal level change can be checked from figures, or directly be monitored through real-time calculation by using observation data. Design of swell wave proportion index finds a pointcut in practical application, and solves the problem of monitoring waves' impact on mooring ships, and would be helpful for arrangements of ship berth and loading. Avoiding use of complex tables polar diagrams of wave-ship resonance indexes describe several factors including wave direction, wave period, ship direction and driving speed at the same time, and can put in real-time observations or model results either.

This work partly fills the gap of research on wave warning for ships, four indexes are all presented graphically and show the influence of wave on ships intuitively. The indexes are practical and propagable, and can be displayed on ships. They are helpful for forecasters and crew to assess the possible wave risk on ships conveniently, precisely and timely. In light of convenience of acquiring relative observations and model results, monitoring of these wave indexes can be carried out by crew on ship after being well trained. This monitoring by ships themselves and together with guidance and service of marine meteorological organization will certainly guarantee safety of ship on sail and on berth. Although these indexes are presented based on requirements of ships in the Yangtze River estuary and Yangshan Port, they can be popularized to any other estuary and port. To be pressed for time, these indexes have not been tested on ship, but application prospect of these wave warning indexes is predictable.

\section{ACKNOWLEDGMENT}

This work benefited from stimulating discussions with our forecasters in Shanghai Marine Meteorological Center and our clients of captains, fishers, port workers and so on. Founding for this research was provided by the Program of Shanghai Meteorological Bureau, No. MS201603.

\section{REFERENCES}

[1] J. L. Yang and X. C. Cao, "Typhoon wave analysis and it's impact on ships safety," Marine Technology, p. 4, 2008.

[2] L. I. Qing lie, "Discussion on damage to ships caused by waves in the areas of coast and shallow waters-consideration aroused by a ship sinking," Navigation of China, pp. 40-43, 2000.

[3] X. B. Chen, L. Zhou, W. L. Shi, L. I. Jing, and X. Chen, "Characteristics of wave and surge fields of typhoon muifa," Advances in Marine Science, pp. 22-30, 2013.

[4] M. Feng, W. Y. Sha, L. I. Yan, and H. U. Yan-Bing, "Development of study on waves offshore," Journal of Pla University of Science \& Technology, pp. 70-76, 2004.

[5] C. Guan, "A review of history and prospect for study of sea wave theory and its forecast in China," Journal of Ocean University of Qingdao, pp. 549-556, 2000.

[6] Y. C. Bai, D. M. Li, and S. Y. Wang, "Changing of fluid speed and tidal level on wave traveling in offshore area," Acta Oceanologica Sinica, vol. 18, no. 3, pp. 92-99, 1996.

[7] K. F. Lambrakos, "Wave-current interaction effects on water velocity and surface wave spectra," Journal of Geophysical Research Oceans, vol. 86, no. C11, pp. 10955-10960, 1981.

[8] J. Wolf and D. Prandle, "Some observations of wave-current interaction," Coastal Engineering, vol. 37, no. 3, pp. 471-485, 1999.

[9] X. P. Sun, China's offshore Marine areas. China Ocean Press, 2006. pp, 139-156.

[10] J. T. Dong, "The check of the wave length formula for the shallow water," Coastal Engineering, pp. 7-10, 1986.

[11] L. I. Meng guo, "Method to determine wave length by using wave dispersion equation," China Harbour Engineering, 2002.

[12] W. M. Organization, Guide to Wave Analysis and Forecasting,World Meteorological Organization, 1998, vol. WMO-No. 702.

[13] S. S. Huang, "Analysisofwavepattern in hurricane wave in nanji sea area," Marine Science Bulleten, pp. 19-23, 1995.

[14] B. Wang and Y. Wang, "Criteria of differentiating swell from wind waves," Journal of oceanography of huanghai and gohai seas, pp. 16-24, 1990.

[15] D. B. Gilhousen and R. Hervey, "Improved estimates of swell from moored buoys," Oceans, pp. 387-393, 2014.

[16] X. Y. Shi, "Study on effects of bimodal spectral and long-period waves upon mooring ships," $\mathrm{Ph}$. D. dissertation, Dalian University of Technology, China, 2013. 
[18] W. Li, B.Zhang, W. Tian, Y. Chen, and Y. Zhou, "Method of ship motion modeling with dynamic positioning in waves," Chinese Journal of Scientific Instrument, pp. 1051-1054, 2007.

[19] W. Kong, Y. E. Heng-Kui, X. H. Yang, Q. R. Chen, and L. I. Zhi-Heng, "Control method for ship moving in longitudinal waves," Ship Science and Technology, vol. 34, no. 3, pp. 36-39, 2012

[20] L. Ms and S. Rw, "The changes in amplitude of short gravity waves on steady non-uniform currents," Journal of Fluid Mechanics, vol 10, no. 4, pp. 529-549, 1961.

[21] F. P. Bretherton and C. J. R. Garrett, "Wavetrains in inhomogeneous moving media," in Porc. Hyperbolic Equations and Waves,Springer Berlin Heidelberg, pp. 98-102, 1970.

[22] J. T. Kirby, "A note on linear surface wave-current interaction over slowly varying topography," Journal of Geophysical Research Oceans, vol. 89, no. C1, pp. 745-747, 1984.

[23] J. Li, "Application of conservation law of wave action flux to wave current interaction," Acta Mechanica Sinica, vol. 12, no. 3, pp. 281-290, 1996.

[24] L. M. Zhou, A. F. Wang, Z. F. Wang, and P. F. Guo, "Wave spectrum characteristics under typhoon wind forcing in coastal waters of the Beibu Bay through numerical simulation by SWAN," Marine Science Bullet, vol. 12, 2010

[25] W. J. Xiao, P. X. Ding, and K. L. Hu, "Numerical calculation of wave fields with tide and currents in Yangtze estuary," Ocean Engineering, pp. 45-52, 2008.
[26] H. E. Junsong and W. Peng, "Empirical formula for ships' short-term wave induced loads," Shipbuilding of China, vol. 52, no. 2, pp. 74-86, 2011.

[27] Y. Pan, "Avoidance of ship synchronous rolling during stormy weather," Journal of Shanghai Maritime University, pp. 21-36, 1988.

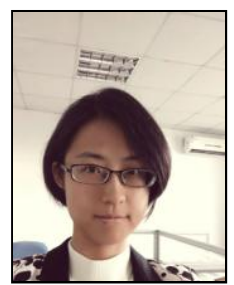

Qi Yang got the master degree of ocean physics from South China Sea Institute of Oceanology Chinese Academy of Science, and now works at Shanghai Marine Meteorological Center, Shanghai Meteorological Service as a weather forecast engineer.

Her publications are as follows: "Q. Yang, G. Y. Chen, and X. D. Shang, "Distribution characteristics of critical periods of Rossby waves and sea-surface height anomaly power spectra in the South China Sea," Journal of Tropical Oceanography, vol. 29, no. 4, pp. 692-699, 2010, 1; Q. Yang, J. J. Ou, and Y. P. Li, "An objective forecast method for sea fog over the Yangshan Sea," Journal of Tropical Oceanography, vol. 32, no. 5, pp. 59-64, 2013; Q. Yang, J. J. Ou, Y. P. Li, and N. L. Huang, "Effects of tidal-current and tidal-level changes on waves in the Yangtze River estuary," vol. 34, no. 5, pp. 19-26, 2015; "X. D. Shang, H. B. Zhu, G. Y. Chen, C. Xu, and Q. Yang," Research on Cyclonic Eddy Change and Phytoplankton Bloom Induced By Typhoons: Case Studies in the South China Sea, Advances in Meteorology, 2015. 